(C) Copyright 2019: Editum. Servicio de Publicaciones de la Universidad de Murcia. Murcia (Spain) ISSN print edition: 0212-9728. ISSN on line edition (http://revistas.um.es/analesps): 1695-2294.

On line edition License Creative Commons 4.0: BY-NC-ND

\title{
Do healthy preterm children have behavior problems?
}

\author{
Miguel Pérez-Pereira*, and Lua Baños
}

Department of Developmental Psychology, University of Santiago de Compostela (Spain)

\begin{abstract}
Título: ¿Los niños prematuros saludables tienen problemas de conducta? Resumen: Objetivo: En este estudio, se compararán los problemas de comportamiento de los niños prematuros sanos y a término. También se estudiará el efecto de las condiciones ambientales y neonatales en la tasa de problemas de comportamiento, prestando especial atención a la depresión materna y al estrés de los padres. Estudios anteriores encontraron tasas de prevalencia significativamente mayores de problemas totales en niños prematuros. La mayoría de estos estudios se llevaron a cabo con niños prematuros menores de 32 semanas de edad gestacional. En contraste, algunos estudios realizados con niños moderadamente prematuros no encontraron diferencias significativas. Método: Evaluamos 108 niños prematuros de bajo riesgo y 33 niños de término completo a través del Child Behavior Checklist cuando tenían 5 años de edad. El estrés y la depresión de sus madres también fueron evaluados. Resultados: No se encontraron diferencias significativas entre los grupos prematuros y los de término completo en cuanto a la internalización o la externalización general de los problemas de conducta, ni a los problemas de conducta más específicos, como la ansiedad, la atención o la agresión. No se encontró ningún efecto de la edad gestacional en la tasa de problemas de conducta. En contraste, el estrés materno, pero no la depresión materna, fue un fuerte predictor de problemas de conducta. Conclusiones: Estos resultados indican que los problemas de conducta no son característicos de los niños prematuros como grupo, sino solo de los niños muy o extremadamente prematuros.

Palabras clave: niños prematuros problemas de comportamiento; factores predictivos; estrés de los padres.
\end{abstract}

\section{Introduction}

Obstetric advances in the last few decades have resulted in a strong increase in survival rates of preterm (PT) born children (Goldenberg, Culhane, Iams \& Romero, 2008), although some of these PT children have had to face academic, social and developmental challenges.

Preterm children are considered to be an at risk population, though not all of them share the same percentage of risk. Important differences exist among preterm children in relation to different biomedical factors. One of these, gestational age (GA), also determines whether other factors coexist. Birth weight (BW) is usually strongly associated with GA, in such a way that the shorter the GA, the lower the BW (excepting those children small for GA). Preterm children can be classified according to GA in 4 groups (Blencowe et al., 2013; Goldenberg et al., 2008):

- Late preterm children (LPT), who have a GA of 34 to 36 weeks;

- Moderately preterm (MPT) children, with a GA between 32-33 week;

* Correspondence address [Dirección para correspondencia]: Miguel Pérez-Pereira, Department of Developmental Psychology, University of Santiago de Compostela. 15782 Santiago de Compostela, (Spain) E-mail: miguel.perez.pereira@usc.es

(Article received: 27-5-2018; revised: 25-8-2018; accepted: 26-5-2019)
Abstract: Background/Objective: In this study, the behavior problems of healthy preterm and full-term children will be compared. The effect of environmental and neonatal conditions on the rate of behavior problems, paying special attention to maternal depression and parental stress, will also be studied.

Previous studies found significantly higher prevalence rates of total problems in preterm children. Most of these studies were carried out with preterm children under 32 weeks of gestational age. In contrast, some studies carried out with moderately preterm children found no significant difference.

Method: We assessed 108 low risk preterm children and 33 full-term children through the Child Behavior Checklist when they were 5 years-old. Their mothers`stress and depression were also assessed.

Results: No significant difference was found between the preterm and the full-term groups for overall internalizing or externalizing behavior problems, or for more fine-grained behavior problems such as anxiety, attention or aggression. No effect of gestational age was found on the rate of behavior problems. In contrast maternal stress, but not maternal depression, was a strong predictor of behavior problems.

Conclusions: These results indicate that behavior problems are not characteristic of preterm children as a group, but only of very or extremely preterm children.

Keywords: preterm children; behavior problems; predictive factors; parental stress.

- Very preterm (VPT) children, with a GA between 28-31 weeks; and

- Extremely preterm (EPT) children, with a GA below 28 weeks.

The risk of suffering medical complications increases as GA and BW are lower. EPT and VPT children have a greater probability of being affected by them than LPT and MPT children (Goldenberg et al., 2008). The most common medical complications affect lungs (bronchopulmonary dysplasia, respiratory distress syndrome) and cerebrum (intraventricular hemorrhage, periventricular leukomalacia), with important consequences for children's development.

Previous studies, which compared behavior problems between preterm (PT) and full term (FT) children, were mostly carried out with extremely (EPT) or very preterm (VPT) children (or very low birth weight (VLBW) or extremely low birth weight (ELBW) children). These studies found significantly higher behavior problem scores in these PT children (Delobel-Ayoub et al., 2009; Gray, Indurkhya \& McCormick, 2004; Hille et al., 2001; Loe, Lee, Luna \& Feldman, 2011; Reijneveld et al., 2006; Rose, Feldman, Rose, Wallace \& McCarton, 1992; Samara, Marlow, Wolke \& Grp, 2008), although the ratios reported varied according to the behavior problem assessed (Miller, Bowen, Gibson, Hand \& Ungerer, 2001). The population of EPT or VPT children showed not only higher behavior problem scores but also a higher per- 
centage of children above the threshold of pathology or with clinically significant problems (Gray et al., 2004; Mansson, Stjernqvist \& Backstrom, 2014; Rose et al, 1992). The estimated percentage of PT children with clinical symptoms was approximately three times as many (Loe, Heller \& Chatav, 2019) or double the norm (Arpi \& Ferrari, 2013; Gray et al., 2004; Hille et al., 2001; Hornman, de Winter, Kerstjens, Bos, \& Reijneveld, 2016; Rose et al., 1992).

From these studies with EPT or VPT children the idea that prematurity is associated with behavior problems has been generalized to the entire population of PT children, although evidence exists that LPT or MPT children do not show significant behavior problem differences when compared to FT children (Gurka, LoCasale-Crouch \& Blackman, 2010; Ketharanathan, Lee \& de Mol, 2011). In any case the evidence is not clear since other studies found somewhat divergent results with MPT children of different ages (De Jong, Verhoeven, Lasham, Meijssen \& Van Baar, 2015; Polic et al., 2017; Potijk, de Winter, Bos, Kerstjens and Reijneveld, 2015), and it was even found that LPT children showed higher scores in behavior problems (externalizing problems, aggressive and oppositional behaviors) than VPT children at 3 years of age (Shah, Robbins, Coelho and Poehlmann, 2013). The discrepancy of the results obtained with LPT children regarding behavior problems is also remarked by Woythaler (2019).

The inconsistencies in the rates of behavior problems found may be due not only to wide variations in the degree of prematurity or birth-weight, but also to other factors such as: the existence of medical complications, the quality of the environment and mother-child interactions in the samples studied (Arpi \& Ferrari, 2013; Cassiano, Gaspardo \& Linhares, 2016; Rose et al., 1992), the age of assessment (Gerstein, Woodman, Burnson, Cheng and Poehlmann-Tynan, 2017; Schappin, Wijnroks, Venema \& Jongmans, 2018) and the particular instrument of assessment used.

Therefore, there is a need for studies carried out with a wide sample of PT children (not only composed of EPT or VPT children), which control some of these confounding factors, in order to assess the real effect of GA. This is the main intention of the present study.

Multiple factors have emerged as potential predictors of behavior problems in PT children. The first one is gestational age (GA). Although those children with lower GA tend to have higher scores in the instruments assessing behavioral problems, different review studies show that GA is not a predictor of behavioral problems (Arpi \& Ferrary, 2013; Cassiano et al., 2016). Other empirical cross-sectional (Cassiano, Gaspardo, Faciroli, Martínez and Linhares, 2017; Cassiano, Provenzi, Linhares, Gaspardo \& Montirosso, 2018) or longitudinal studies (Gerstein et al., 2017; Santos, Barros, Munhoz and Matijasevich, 2017) found no significant effect of GA on behavior problems for PT children at different ages (in a range between 16 months up to 11 years of age).

Evidence in favor of gender effect is not clear at all, and the impression is that differences may increment with age.
For instance, Cosentino-Rocha, Klein and Martins-Linhares, (2014) did not find gender differences in behavior problems at 18-36 months of age. In a large-scale study with 1074 extremely preterm children, Lowe et al. (2019) found that CBCL scores were similar for girls and boys (mean age 24 months) with the exception of the pervasive developmental problem scale where girls scored significantly lower. Samara and colleagues (2008), however, found that, studying preschool age children, internalizing problems are more highly associated with girls and externalizing problems with boys; Potijk et al. (2015) found that co-occurrence of developmental and behavioral problems was much more common among boys than among girls. In addition, Vederhus et al. (2015) found that there was an improvement of behavioral problems from childhood (10 years of age) to adulthood (18 years of age) in EPT boys, but not in girls.

The effect of medical neonatal problems on behavior difficulties in PT children is far from being well established. In a recent review of the papers published between 2009 and 2014 on the relationships between clinical neonatal variables (such as intraventricular hemorrhage, periventricular leukomalacia or bronchopulmonary dysplasia) and behavioral and emotional problems in children born preterm, Cassiano et al. (2016) concluded that prematurity combined with neonatal risk factors increased the risk of behavioral and/or emotional problems. In contrast, some studies reported that GA or medical factors did not predict behavior difficulties ( $T$ scores in the CBCL higher than 63) between 6 and 8 years of age (Rose et al., 1992; Miller et al., 2001).

Low parental stress seems to be a protective factor, which moderates the existence of behavioral problems in PT children (Arpi \& Ferrari, 2013; Cassiano et al., 2016) and the decrease in externalizing problems over a 1 -year period in PT preschoolers who already had behavior problems (Schappin et al., 2018). In contrast, high parental stress or maternal distress (a composite of maternal stress and depression) is associated to later appearance of behavioral difficulties in PT children (Gray et al., 2004; Miceli, Goeke-Morey, Whitman, Kolberg, Miller-Loncar and White, 2000; Miller et al., 2001; Rose at al., 1992). In this connection, the level of stress of the mothers of VPT children seems to increase as they grow, as compared to the mothers of FT children (Gray, Edwards, O'Callahan \& Cuskelly, 2012; Gray, Edwards, O'Callahan, Cuskelly \& Gibbons 2013), which may be a reason why PT children could show higher levels of behavioral problems than FT children at preschool and school age.

Socio-economic characteristics of the families (SES) (families with lower income, lower maternal education, early motherhood...) were found to be related to total as well as to externalizing and internalizing behavioral problems of PT children in different studies (Cassiano et al., 2018; de Laat, Essink-Bot, van Wassenaer-Leemhuis \& Vrijkotte, 2016; Monte Cassiano, Gaspardo, Bucker Furini, Martinez, \& Martins Linhares, 2016, Rose et al., 1992; Santos et al, 2017; Schappin et al., 2018). Maternal education, however, (an in- 
dex often used to compute SES) was not found to have any significant effect on behavioral problems (Miller et al., 2001).

The aim of this study is to compare the rate of behavioral problems between a sample of low risk PT children (GA range: 25-36) and a sample of full-term (FT) children. The influence of environmental and neonatal conditions on the rate of behavioral problems will also be studied, with special attention to parenting stress and maternal depression.

The hypotheses of the study are: 1) no differences will be found between the FT and PT groups in the rate of behavior problems or maternal depression and stress given the low risk condition of the PR group; 2) maternal stress and depression will have a predictive role on internalizing, externalizing and total behavior problems, and maternal education will have a significant although less important effect; 3) gestational age will not have any significant predictive role on behavior problems, nor will gender.

\section{Method}

\section{Participants}

The participants of this study were 108 low risk PT children and 33 FT children of 5 years of age.

The PT group had a mean GA (and SD) of 32.62 (2.41) weeks, a mean birth weight (BW) of 1721.70 grams (435.36), and a mean Apgar score (first minute) of 7.94 (1.30).

The FT group had a mean GA of 39.70 (1.48) weeks, a mean BW of 3373.83 grams (433.09), and a mean Apgar score of 8.13 (1.20).

To select the PT sample, a series of exclusion criteria were established. These included: cerebral palsy, periventricular leukomalacia, intraventricular hemorrhage (>grade II), hydrocephalus, genetic malformations, chromosome syndromes, metabolic syndromes associated to mental retardation, severe motor or sensorial impairments and Apgar score lower than 6 at 5 minutes in preterm children.

Therefore, this sample of PT children may be considered as low risk.

As Table 1 shows, the FT and the PT groups were comparable in terms of maternal education $\left(\chi^{2}(2)=3.945, \mathrm{p}=\right.$ $.139)$ and gender distribution $\left(\chi^{2}(1)=.000, \mathrm{p}=.997\right): 52.3 \%$ and $51 \%$ of PT and FT children respectively were of masculine gender.

Table 1. Distribution of the groups by maternal education.

\begin{tabular}{lllll}
$\begin{array}{l}\text { Maternal } \\
\text { Education }\end{array}$ & 1: Basic & $\begin{array}{l}\text { 2: High school, } \\
\text { Technical education }\end{array}$ & 3: University & Total \\
FT & $22(14.66 \%)$ & $75(50 \%)$ & $53(35.33 \%)$ & 150 \\
PT & $13(26.53 \%)$ & $19(38.77 \%)$ & $17(34.69 \%)$ & 49 \\
Total & 35 & 94 & 70 & 199 \\
\hline
\end{tabular}

\section{Instruments}

The following assessment instruments were administered when the children were 5 years old ( \pm 1 month).

The Child Behavior Checklist (CBCL) (Achembach \&
Rescorla, 2000) for children aged $1^{1 / 2}-5$ was administered to the participants' mothers. The CBCL is the most widely used instrument to assess behavior problems in previous studies (Cassiano et al, 2016).

The CBCL consists of 99 items plus an open question. The items are integrated in 7 empirically based scales. These scales merge into two big syndrome scales: Internalizing Problems and Externalizing Problems, which, in turn, give a Total Problems score.

A. Internalizing Problems:

1. Emotional reactive

2. Anxious/Depressed

3. Somatic complaints

4. Withdrawal

B. Externalizing Problems

6. Attention problems

7. Aggressive behavior

There are also two residual scores: 5. Sleep problems and Other problems, which are not included in the two former syndrome scales. The Total Problems score consists of the sum of the seven aforementioned empirically based scales (plus other problems).

The Parenting Stress Index - Short Form (PSI-SF) (Abidin, 1995; Díaz-Herrero, López-Pina, Pérez-López, Brito \& Martínez-Fuentes, 2011) is a questionnaire comprising 36 items that parents must respond to on a 5-point Likert-type scale. It attempts to evaluate stress experienced during parenting. There are three subscales:

1. Parental Distress: the distress a parent is experiencing in his/her role as a parent.

2. Parent-Child Dysfunctional Interaction: the parent's perception that his or her child does not meet expectations, and interactions with the child are not reinforcing him/her as a parent.

3. Difficult Child: the child is perceived as difficult to manage because of problems in self-regulatory processes.

The total stress index (used in this paper) is the sum of the three subscales and provides an indication of the overall level of parenting stress.

The Maternal Depression Scale (CES-D; Radloff, 1977) is a questionnaire with 20 items that mothers must respond to on a 4-point Likert-type scale, which evaluates the existence of depressive traits in the mothers of the children studied. A score of over 16 is considered to indicate depressive traits.

In addition, socio-demographic and health data were gathered through an interview with the mothers shortly after the children's birth, and again when the children were 4 years old. Among the information collected were data on maternal and paternal educational level and profession, mother's age at birth, problems during pregnancy, consumption of tobacco by mothers, child's Apgar score, birth weight, child's medical problems, use of medication, length of stay at NICU (neonatal intensive care unit), day care attendance, data on 
the development of autonomy (sphincter control, dressing...), composition of the family, etc.

\section{Analyses performed}

One-way ANOVA analyses were performed to compare the results of the PT and the FT groups in the CBCL direct scores, as well as in the PSI-SF and the CES-D scales.

In order to check if pathology levels were more frequent in PT than in FT children, the PT and FT children were sorted into two groups according to the $\mathrm{T}$ score obtained in the CBCL: group 1) non-pathology group: those children with a $\mathrm{T}$ score lower than 64, and 2) pathology group those children with a T score of 64 or above. Pearson's Chi squared analyses were performed on the distribution of the two groups of PT and FT children within these two groups of pathology and non-pathology.

Finally, linear regression analyses were performed to assess the possible effect of predictive factors. The Dependent variables were in turn: Internalizing problems, Externalizing problems, and Total problems. The predictors were tested in two models. Model 1 included gender, gestational age, and maternal education; and Model 2 included gender, gestational age (in weeks), maternal education, parental stress total score, and maternal depression score.

\section{Procedure}

The mothers of the children filled in the Child Behavior Checklist (CBCL) $1^{1 / 2}-5$ years (Achembach \& Rescorla, 2000) when the children were 5 years old.

The mothers also filled in the Parenting Stress IndexShort Form (Abidin, 1995, Díaz-Herrero et al., 2011), and the CES-D (Radloff, 1977) at this same time. The interview with the mothers took place when the children were newborn and 4 years of age.

Previous informed consent was obtained from the mothers. The research was approved by the Ethics Committee of the University of Santiago de Compostela and was performed in accordance with the Helsinki Declaration.

\section{Results}

1) The comparison of the raw scores obtained by the PT and the FT groups in the CES-D and the PSI-SF are shown in Table 2, and they clearly point to the inexistence of significant differences between groups. Therefore, it is possible to affirm that the mothers of the PT and the FT children did not differ in the stress or the depression traits they had.

Table 2. Mean score (SD) and comparisons between groups in the PSI-SF, the CES-D, and the CBCL scales.

\begin{tabular}{|c|c|c|c|c|c|}
\hline & Preterm & Full-term & $\mathrm{F}$ & Signific. & $\mathrm{df}$ \\
\hline$\overline{\text { PSI-SF }}$ & $64.67(14.72)$ & $67.42(13.87$ & .893 & .346 & 131 \\
\hline CES-D & $9.10(6.32)$ & $10.73(8.81)$ & 1.238 & .268 & 122 \\
\hline CBCL-Total problems & $32.12(32.33)$ & $32.33(16.86)$ & .004 & .950 & 140 \\
\hline Externalizing problems & $11.37(6.47)$ & $10.73(5.62)$ & .264 & .608 & 140 \\
\hline Internalizing problems & $8.38(6.16)$ & $9.27(6.25)$ & .528 & .469 & 140 \\
\hline Emotional reactivity & $1.81(2.08)$ & $2.09(2.26)$ & .454 & .501 & 140 \\
\hline Anxiety / Depression & $2.90(2.20)$ & $3.33(2.14)$ & .997 & .320 & 140 \\
\hline Somatic complaints & $2.01(2.08)$ & $2.36(2.07)$ & .732 & .394 & 140 \\
\hline Introverted & $1.66(1.77)$ & $1.48(1.54)$ & .254 & .615 & 140 \\
\hline Sleep & $3.02(2.80)$ & $3.03(2.73)$ & .000 & .983 & 140 \\
\hline Attention & $2.64(1.92)$ & $3.06(1.74)$ & 1.268 & .262 & 140 \\
\hline Aggressive & $8.73(5.26)$ & $7.67(4.49)$ & 1.104 & .295 & 140 \\
\hline
\end{tabular}

The comparison of the results obtained by the PT and the FT groups in the CBCL indicates that there were no significant differences in the scores of the Internalizing and Externalizing problems or in the Total Problems score of the CBCL. Nor were any differences found for more finegrained behavior problems such as attention problems, aggressive problems, anxiety or withdrawal (see also Table 2 lower part). The mean scores obtained correspond to medium $\mathrm{T}$ scores between 48 to 53 and percentiles between 38 and 62 .

2) The distribution of the PT and the FT groups into the 2 (non-pathology / pathology) groups appears in Table 3. The Chi squared analysis indicates that there is no significant difference between the two groups in total CBCL problems $\left(\chi^{2}\right.$ $(1)=.012, p=.913)$, internalizing problems $\left(\chi^{2}(1)=.019\right.$, $p=.891)$ or externalizing problems $\left(\chi^{2}(1)=.937, p=.333\right)$.
In general terms, the percentage of clinical problems in the two samples of FT and PT children is low (below 10\% in all cases), and a higher incidence of internalizing problems is observed for the two groups (see Table 3).

Table 3. Distribution of the PT and FT samples into the non-pathology and the pathology groups.

\begin{tabular}{llll}
\hline & Non-Pathology $(T<64)$ & Pathology $(T \geq 64)$ & Total \\
\hline Total problems & & & \\
PT & $102(94.45 \%)$ & $6(5.55 \%)$ & 108 \\
FT & $31(93.94 \%)$ & $2(6.06 \%)$ & 33 \\
Externalizing & & & \\
PT & $105(97.23 \%)$ & $3(2.77 \%)$ & 108 \\
FT & $33(100 \%)$ & $0(0 \%)$ & 33 \\
Internalizing & & & \\
PT & $99(91.67 \%)$ & $9(8.33 \%)$ & 108 \\
FT & $30(90.91 \%)$ & $3(9.09 \%)$ & 33 \\
\hline
\end{tabular}


3) The results of the Regression analyses (Tables 4, 5 and 6) indicate that the variables introduced in Model 1 (gender, gestational age, and maternal education) have a minor, not significant, effect on behavior problems. The introduction of parental stress and maternal depression in Model 2 increases the variance explained (change in $R^{2}$ ) $32.3 \%, 23.6 \%$, and 29.7\% for Total Problems, Internalizing and Externalizing problems, respectively. Therefore Model 2 has a highly $(p<.001)$ significant effect on the variance of the dependent variables. In all cases, parental stress always has a highly significant $(p<.001)$ single effect (standardized $\beta$ ). In contrast, maternal depression has no significant effect on the variance of the dependent variables.

Table 4. Regression analysis: Predictors of CBCL Total behavior problems.

\begin{tabular}{|c|c|c|c|c|c|c|c|c|c|}
\hline Predictors & Standardized $\beta$ & Sign. & $\mathrm{R}^{2}$ & Change in $\mathrm{R}^{2}$ & Change in $\mathrm{F}$ & Significance Change in F & $F$ & & $p$ \\
\hline Model 1 & & & .043 & .043 & 1.738 & .163 & 1.738 & 3,117 & .163 \\
\hline Gender & -.017 & .851 & & & & & & & \\
\hline GA & .027 & .767 & & & & & & & \\
\hline Maternal ed. & -.201 & .030 & & & & & & & \\
\hline Model 2 & & & .366 & .323 & 29.271 & $<.001$ & 13.255 & 5,115 & $<.001$ \\
\hline Gender & -.103 & .176 & & & & & & & \\
\hline GA & .017 & .823 & & & & & & & \\
\hline Maternal ed. & -.137 & .077 & & & & & & & \\
\hline Parental stress & .540 & .000 & & & & & & & \\
\hline Maternal depr. & .086 & .297 & & & & & & & \\
\hline
\end{tabular}

Table 5. Regression analysis: Predictors of CBCL Internalizing problems.

\begin{tabular}{|c|c|c|c|c|c|c|c|c|c|}
\hline Predictors & Standardized $\beta$ & Sign. & $\mathrm{R}^{2}$ & Change in $\mathrm{R}^{2}$ & Change in $\mathrm{F}$ & Significance Change in F & $F$ & $d f$ & $p$ \\
\hline Model 1 & & & .052 & .052 & 2.151 & .098 & 2.151 & 3,117 & .098 \\
\hline Gender & -.012 & .894 & & & & & & & \\
\hline GA & .032 & .726 & & & & & & & \\
\hline Maternal ed. & -.222 & .016 & & & & & & & \\
\hline Model 2 & & & .289 & .236 & 19.119 & $<.001$ & 9.338 & 5,115 & $<.001$ \\
\hline Gender & -.087 & .279 & & & & & & & \\
\hline GA & .023 & .776 & & & & & & & \\
\hline Maternal ed. & -.161 & .049 & & & & & & & \\
\hline Parental stress & .443 & .000 & & & & & & & \\
\hline Maternal depr. & .110 & .209 & & & & & & & \\
\hline
\end{tabular}

Table 6. Regression analysis: Predictors of CBCL Externalizing problems.

\begin{tabular}{|c|c|c|c|c|c|c|c|c|c|}
\hline Predictors & Standardized $\beta$ & Sign. & $\mathrm{R}^{2}$ & Change in $\mathrm{R}^{2}$ & Change in $\mathrm{F}$ & Significance Change in $\mathrm{F}$ & $F$ & $d f$ & $p$ \\
\hline Model 1 & & & .040 & .040 & 1.608 & .191 & 1.608 & 3,117 & .191 \\
\hline Gender & .006 & .945 & & & & & & & \\
\hline GA & .038 & .678 & & & & & & & \\
\hline Maternal ed. & -.190 & .039 & & & & & & & \\
\hline Model 2 & & & .337 & .297 & 25.762 & $<.001$ & 11.678 & 5,15 & $<.001$ \\
\hline$\overline{\text { Gender }}$ & -.071 & .360 & & & & & & & \\
\hline GA & .029 & .704 & & & & & & & \\
\hline Maternal ed. & -.144 & .068 & & & & & & & \\
\hline Parental stress & .555 & $<.001$ & & & & & & & \\
\hline Maternal depr. & -.007 & .932 & & & & & & & \\
\hline
\end{tabular}

In general terms, the variables introduced in Model 1 do not have an effect on the variance explained with the exception of maternal education, which has a significant effect on Total, Internalizing and Externalizing problems (see standardized $\beta$ significance). The effect of maternal education does not reach significant values when parental stress and maternal depression are introduced in Model 2, with the exception of the effect for Internalizing problems $(p=.049)$. Importantly, gestational age does not have a significant effect on any of the CBCL measures, and, therefore, does not seem to have any effect on the existence of behavior problems. Nor does gender have an effect.

\section{Discussion}

The comparisons of the results obtained by the two groups in the variables assessed indicate that there was no significant difference between the stress scores of the mothers of the PT and FT children. This result contrasts with other studies which found higher stress levels in the mothers of PT or 
high-risk children around 10 months of age (Solis \& Abidin, 1991; Gray et al., 2013). It is necessary to bear in mind that our participants were assessed at 5 years of age. Mean raw scores obtained by the mothers of the PT and the FT children correspond to percentiles 35 and 45 in the PSI-SF, respectively, which point to slightly below average stress levels.

No differences were found between groups in maternal depression, the same as results in other studies have also shown with mothers of PT babies (Gray et al., 2012, 2013). No indication of depressive traits is derived from the mean scores obtained by the mothers of the two groups.

In the present study no significant differences were found between the PT and the FT groups in any of the measures taken with the CBCL: Total problems scores, internalizing or externalizing problems. Nor were differences found in more specific measures. The present results are in sharp contrast with the results found in most studies carried out with EPT or VPT children (Arpi \& Ferrari, 2013; Cassiano et al., 2016) or MPT or LPT children (De Jong et al., 2015; Hille et al., 2001; Potijk et al., 2015; Shah et al., 2013). The results we found coincide, however, with those carried out with LPT or MPT children by Gurka et al. (2010), by Ketharanathan et al. (2011), or with a general sample of healthy PT children (Santos et al., 2017), and seem to indicate that when PT children do not have biomedical complications, they do not show more behavioral problems than FT children.

In relation to the incidence of clinically relevant behavior problems, the results found for internalizing, externalizing or total problems were very similar for the FT and the PT groups, and always below 10\%. There were more children with scores above the cut off for pathology in internalizing problems in both groups of children. In any case, we could not confirm that behavior problems were three times as many (Loe, Heller \& Chatav, 2019) or double the percentage in PT children than in FT children (Arpi \& Ferrari, 2013; Gray et al., 2004; Hille et al., 2001; Hornman et al., 2016; Rose et al., 1992).

In relation to the factors predicting behavior problems, maternal education was the only variable of Model 1 which had a significant effect on total behavior problems, internalizing and externalizing behavior problems at 5 years of age. The lower the maternal level of studies, the higher the scores in behavior problems. In any case the effect of the three variables of Model 1 (gestational age, gender and maternal education) on behavior problems was low (4\% or $5 \%$ of variance explained). Therefore, our results are in line with other

\section{References}

Abidin, R. R. (1995). Parenting Stress Index. Third Edition. Professional manual. Odessa, FL: Psychological Assessment Resources.

Achembach, T. M., \& Rescorla, L. A. (2000). Manual for the ASEBA Preschool Forms \& Profiles. Burlington, VT: University of Vermont, Research Center for Children, Youth, \& Families.

Arpi, E., \& Ferrari, F. (2013). Preterm birth and behaviour problems in infants and preschool-age children: a review of the recent literature. De- studies in which a significant effect of maternal education was found on externalizing (Schappin et al., 2018), or internalizing and total problems at 6 years of age (Cassiano et al., 2018; Gerstein et al., 2017; Santos et al., 2017; Rose et al., 1992;), with a similar percentage of variance explained (7\%).

Our results confirm that GA does not seem to have a predictive role on behavior problems (Arpi \& Ferrari, 2013; Cassiano et al., 2016; Cassiano et al., 2017; Cassiano et al., 2018; Gerstein et al., 2017; Santos et al., 2017), while other factors seem to have a higher predictive effect on behavior problems than GA; gender however, has no predictive effect on behavior problems, which is in agreement with Loe, Heller \& Chatav (2019) findings.

The variables introduced in Model 2 (maternal depression and parenting stress) highly increased the variance explained for internalizing, externalizing and total behavior problems. Parental stress was the only variable that had a significant single effect, our results confirming those obtained by other studies (Arpi \& Ferrari, 2013; Cassiano et al., 2016; Gray et al., 2004; Miceli et al., 2000; Miller et al., 2001; Rose et al., 1992, Schappin et al., 2018).

In contrast, maternal depression does not seem to have any causal effect on the appearance of behavior problems in the children, at least when measured through the CES-D. Therefore, it is parental stress that seems to have a stronger effect on the appearance of behavior problems in their children.

\section{Conclusions}

Low risk PT children do not have a higher level of behavioral problems that their FT peers. The percentage of PT children with clinically relevant levels of behavior problems is similar to that of FT children, and this percentage is very low when compared to other studies.

No effect of GA on the rate of behavior problems was found. In contrast, the predominant conclusion of this study is that maternal stress does seem to be the strongest predictor of behavior problems.

One limitation of this study is that we used reports filled in by the mothers. It would be interesting to gather information from teachers or direct clinical assessment.

Acknowledgments.- This research was funded by the Ministerio Economia Industria y Competitividad of the Spanish Government (grants PSI2011-23210 and PSI2015-66697-R to the first author).

velopmental Medicine and Child Neurology, 55(9), 788-796. doi: 10.1111/dmcn.12142.

Blencowe, H., Cousens, S., Chou, D., Oestergaard, M., Say, L., Moller, A., Kinney, M., Lawn, J., \& Born Too Soon Preterm Birth Action Group. (2013). Born Too Soon: The global epidemiology of 15 million preterm births. Reproductive Health, 10 (Suppl 1)(S2), 1-16. doi: 10.1186/17424755-10-S1-S2. 
Cassiano, R. G. M., Gaspardo, C. M., \& Linhares, M. B. M. (2016). Prematurity, neonatal health status, and later child behavioral/emotional problems: A systematic review. Infant Mental Health Journal, 37(3), 274288. doi: 10.1002/imhj.21563.

Cassiano, R. G. M., Gaspardo, C. M., Faciroli, R. A. D., Martinez, F. E., \& Linhares, M. B. M. (2017). Temperament and behavior in toddlers born preterm with related clinical problems. Early Human Development, 112, 18. doi: 10.1016/j.earlhumdev.2017.06.003

Cassiano, R. G. M., Provenzi, L., Linhares, M. B. M., Gaspardo, C. M., \& Montirosso, R. (2018). Maternal sociodemographic factors differentially affect the risk of behavioral problems in Brazilian and Italian preterm toddlers. Infant Behavior \& Development, 50, 165-173. doi:10.1016/j.infbeh.2017.12.006

Cosentino-Rocha, L., Klein, V. C., \& Martins-Linhares, M. B. (2014). Effects of preterm birth and gender on temperament and behavior in children. Infant Behavior \& Development, 37(3), 446-456. doi: 10.1016/j.infbeh.2014.04.003.

de Jong, M., Verhoeven, M., Lasham, C. A., Meijssen, C. B., \& van Baar, A. L. (2015). Behaviour and development in 24-month-old moderately preterm toddlers. Archives of Disease in Childhood, 100(6), 548-553. doi: 10.1136/archdischild-2014-307016.

de Laat, S. A. A., Essink-Bot, M.-L., van Wassenaer-Leemhuis, A. G., \& Vrijkotte, T. G. (2016). Effect of socioeconomic status on psychosocial problems in 5-to 6-year-old preterm- and term-born children: the ABCD study. European Child \& Adolescent Psychiatry, 25(7), 757-767. doi: 10.1007/s00787-015-0791-4.

Delobel-Ayoub, M., Arnaud, C., White-Koning, M., Casper, C., Pierrat, V., Garel, M., Burguet A., Roze J., Matis J., Picaud J., Kaminski M., \& Larroque B. (2009). Behavioral problems and cognitive performance at 5 years of age after very preterm birth: the EPIPAGE Study. Pediatrics, 123(6), 1485-1492. doi: 10.1542/peds.2008-1216.

Díaz-Herrero, Á., López-Pina, J A., Pérez-López, J., Brito, A., \& MartínezFuentes, M. T. (2011). Validity of the Parenting Stress Index-Short Form in a Sample of Spanish Fathers. The Spanish Journal of Psychology, 14(02), 990-997. doi: 10.5209/rev_SJOP.2011.v14.n2.44.

Gerstein, E. D., Woodman, A. C., Burnson, C., Cheng, E. R., \& Poehlmann-Tynan, J. (2017). Trajectories of Externalizing and Internalizing Behaviors in Preterm Children Admitted to a Neonatal Intensive Care Unit. Journal of Pediatrics, 187, 111-118. doi: 10.1016/j.jpeds.2017.04.047

Goldenberg, R. L., Culhane, J. F., Iams, J. D., \& Romero, R. (2008). Preterm birth 1 - Epidemiology and causes of preterm birth. Lancet, 371(9606), 75-84. doi: 10.1016/s0140-6736(08)60074-4.

Gray, P. H., Edwards, D. M., O'Callaghan, M. J., \& Cuskelly, M. (2012). Parenting stress in mothers of preterm infants during early infancy. Early Human Development, 88(1), 45-49. doi: 10.1016/j.earlhumdev.2011.06.014.

Gray, P. H., Edwards, D. M., O'Callaghan, M. J., Cuskelly, M., \& Gibbons, K. (2013). Parenting stress in mothers of very preterm infants - Influence of development, temperament and maternal depression. Early Human Development, 89(9), 625-629. doi: 10.1016/i.earlhumdev.2013.04.005

Gray, R. F., Indurkhya, A., \& McCormick, M. C. (2004). Prevalence, stability, and predictors of clinically significant behavior problems in low birth weight children at 3,5 , and 8 years of age. Pediatrics, 114(3), 736743. doi: $10.1542 /$ peds.2003-1150-L.

Gurka, M. J., LoCasale-Crouch, J., \& Blackman, J. A. (2010). Long-term cognition, achievement, socioemotional, and behavioral development of healthy late-preterm infants. Archives of Pediatrics and Adolescent Medicine, 164(6), 525-532. doi: 10.1001/archpediatrics.2010.83.

Hille, E. T. M., den Ouden, A. L., Saigal, S., Wolke, D., Lambert, M., Whitaker, A., Pinto-Martin, J. A., Hoult, L., Meyer, R., Feldman, J. F., Verloove-Vanhorick, S. P., \& Paneth, N. (2001). Behavioural problems in children who weigh $1000 \mathrm{~g}$ or less at birth in four countries. Lancet, 357(9269), 1641-1643, doi: 10.1016/s0140-6736(00)04818-2.

Hornman, J., de Winter, A. F., Kerstjens, J. M., Bos, A. F., \& Reijneveld, S. A. (2016). Emotional and Behavioral Problems of Preterm and FullTerm Children at School Entry. Pediatrics, 137(5). doi: 10.1542/peds.2015-2255

Ketharanathan, N., Lee, W., \& de Mol, A. C. (2011). Health-related quality of life, emotional and behavioral problems in mild to moderate prematures at (pre-)school age. Early Human Development, 87, 705-709. doi: 10.1016/j.earlhumdev.2011.05.011

Loe, I. M., Lee, E. S., Luna, B., \& Feldman, H. M. (2011). Behavior problems of 9 to 16 year-old preterm children: Biological, sociodemographic, and intellectual contributions. Early Human Development, 87(4), 247 252. doi:10.1016/j.earlhumdev.2011.01.023

Loe, I. M., Heller, N. A., \& Chatav, M. (2019). Behavior problems and executive function impairments in preterm compared to full term preschoolers. Early Human Development, 130, 87-95. doi:10.1016/j.earlhumdev.2019.01.014

Lowe, J. R., Fuller, J. F., Do, B. T., Vohr, B. R., Das, A., Hintz, S. R., . . Human Dev Neonatal Res, N. (2019). Behavioral problems are associated with cognitive and language scores in toddlers born extremely preterm. Early Human Development, 128, 48-54. doi:10.1016/j.earlhumdev.2018.11.007

Mansson, J., Stjernqvist, K., \& Backstrom, M. (2014). Behavioral outcomes at corrected age 2.5 years in children born extremely preterm. Journal of Developmental and Behavioral Pediatrics, 35(7), 435-442. doi: $10.1097 / \mathrm{dbp} .0000000000000082$.

Miceli, P. J., Goeke-Morey, M. C., Whitman, T. L., Kolberg, K. S., MillerLoncar, C., \& White, R. D. (2000). Brief report: Birth status, medical complications, and social environment: Individual differences in development of preterm, very low birth weight infants. Journal of Pediatric Psychology, 25(5), 353-358. doi: 10.1093/jpepsy/25.5.353

Miller, M., Bowen, J. R., Gibson, F. L., Hand, P. J., \& Ungerer, J. A. (2001). Behaviour problems in extremely low birthweight children at 5 and 8 years of age. Child: Care, Health and Development, 27(6), 569-581.

Monte Cassiano, R. G., Gaspardo, C. M., Bucker Furini, G. C., Martinez, F. E., \& Martins Linhares, M. B. (2016). Impact of neonatal risk and temperament on behavioral problems in toddlers born preterm. Early $\mathrm{Hu}$ man Development, 103, 175-181. doi: 10.1016/j.earlhumdev.2016.09.015.

Polic, B., Bubic, A., Mestrovic, J., Markic, J., Kovacevic, T., Furlan, I. A., et al. (2017). Emotional and behavioral outcomes and quality of life in school-age children born as late preterm: retrospective cohort study. Croatian Medical Journal, 58(5), 332-341. doi: 10.3325/cmi.2017.58.332

Potijk, M. R., de Winter, A. F., Bos, A. F., Kerstjens, J. M., \& Reijneveld, S. A. (2015). Behavioural and emotional problems in moderately preterm children with low socioeconomic status: a population-based study. European Child \& Adolescent Psychiatry, 24(7), 787-795. doi: 10.1007/s00787-014-0623-y.

Radloff L.S. (1977). The CES-D Scale: A self-report depression scale for research in the general population. Applied Psychological Measurement, 1(3), 385-401

Reijneveld, S. A., de Kleine, M. J. K., van Baar, A. L., Kollee, L. A. A., Verhaak, C. M., Verhulst, F. C., \& Verloove-Vanhorick, S. P. (2006). Behavioural and emotional problems in very preterm and very low birthweight infants at age 5 years. Archives of Disease in Childhood-Fetal and Neonatal Edition, 91(6), F423-F428. doi: 10.1136/adc.2006.093674

Rose, S. A., Feldman, J., Susan L. Rose, Wallace, I. F., \& McCarton, C. (1992). Behavior problems at 3 and 6 years: Prevalence and continuity in full-terms and preterms. Development and Psychopathology, 4, 361-374.

Samara, M., Marlow, N., Wolke, D., \& Grp, (2008). Pervasive behavior problems at 6 years of age in a total-population sample of children born at $<=25$ weeks of gestation. Pediatrics, 122(3), 562-573. doi: 10.1542/peds.2007-3231

Santos, I. S., Barros, F. C., Munhoz, T., \& Matijasevich, A. (2017). Gestational age at birth and behavioral problems from four to 11 years of age: birth cohort study. Bmc Pediatrics, 17(1), 184. doi:10.1186/s12887017-0936-3

Schappin, R., Wijnroks, L., Venema, M. U., \& Jongmans, M. (2018). Exploring predictors of change in behavioral problems over a 1-year period in preterm born preschoolers. Infant Behavior \& Development, 50, 98 106. doi:10.1016/j.infbeh.2017.12.003

Shah, P. E., Robbins, N., Coelho, R. B., \& Poehlmann, J. (2013). The paradox of prematurity: The behavioral vulnerability of late preterm infants and the cognitive susceptibility of very preterm infants at 36 months post-term. Infant Behavior \& Development, 36(1), 50-62. doi: 10.1016/j.infbeh.2012.11.003 
Solis, M. L., \& Abidin, R. R. (1991). The Spanish version Parenting Stress Index: A psychometric study. Journal of Clinical and Child Psychology, 20(4), 372-378.

Vederhus, B. J., Eide, G. E., Natvig, G. K., Markestad, T., Graue, M., \& Halvorsen, T. (2015). Health-related quality of life and emotional and behavioral difficulties after extreme preterm birth: developmental trajectories. PeerJ 3:e738; DOI 10.7717/peerj.738

Woythaler, M. (2019). Neurodevelopmental outcomes of the late preterm infant. Seminars in Fetal \& Neonatal Medicine, 24(1), 54-59. doi: 10.1016/j.siny.2018.10.002 